University of the Pacific

Scholarly Commons

\title{
Vico and Imagination: An Ingenious Approach to Educating Lawyers with Semiotic Sensibility
}

Francis J. Mootz III

University of the Pacific, McGeorge School of law, jmootz@pacific.edu

Follow this and additional works at: https://scholarlycommons.pacific.edu/facultyarticles

Part of the Jurisprudence Commons, Legal Education Commons, and the Legal History Commons

\section{Recommended Citation}

Vico and Imagination: An Ingenious Approach to Educating Lawyers with Semiotic Sensibility, 22 Int'l J. for the Semiotics of L. 11 (2009).

This Article is brought to you for free and open access by the McGeorge School of Law Faculty Scholarship at Scholarly Commons. It has been accepted for inclusion in McGeorge School of Law Scholarly Articles by an authorized administrator of Scholarly Commons. For more information, please contact mgibney@pacific.edu. 


\title{
Vico and Imagination: An Ingenious Approach to Educating Lawyers with Semiotic Sensibility
}

\author{
Francis J. Mootz III
}

Published online: 17 January 2009

(C) Springer Science+Business Media B.V. 2009

\begin{abstract}
Law is a specialized semiotic realm, but lawyers generally are ignorant of this fact. Lawyers may manage meaning, but they also are managed by meaning. Seemingly trapped by the weight of pre-existing signs, their attempts to manage these meanings generally are limited to technical interventions and instrumentalist strategies. Signs have power over lawyers because they are embedded in narratives, a semiotic economy that confronts the lawyer as "given" even though it is dynamic and constantly under construction. Most lawyers do not make meaning through legal narratives; rather, they parrot bits of the controlling narratives in response to certain problems. Because clients often can achieve their objectives when their lawyers crudely manipulate the symbols of law, these endeavors pay very well. Well-paid lawyers tend not to ask too many questions. Consequently, semiotics is, at best, misunderstood by lawyers; more likely it is wholly unknown. A lawyer's avowed instrumentalism is the very problem to be addressed in this regard. For the scope of discussion, I refer to Vico's famous On the Study Methods of Our Time and draw my conclusion for the lawyer of our time.
\end{abstract}

\section{Introduction}

Law is a specialized semiotic realm, but lawyers generally are ignorant of this fact. Lawyers may manage meaning, but they also are managed by meaning. Seemingly trapped by the weight of pre-existing signs, their attempts to manage these meanings generally are limited to technical interventions and instrumentalist strategies. Signs have power over lawyers because they are embedded in narratives, a semiotic economy that confronts the lawyer as "given" even though it is dynamic and

F. J. Mootz III (ه)

William S. Boyd School of Law, Box 451003, 4505 South Maryland Parkway, Las Vegas, NV 89154-1003, USA

e-mail: Jay.Mootz@unlv.edu 
constantly under construction. Most lawyers do not make meaning through legal narratives; rather, they parrot bits of the controlling narratives in response to certain problems. Because clients often can achieve their objectives when their lawyers crudely manipulate the symbols of law, these endeavors pay very well. Well-paid lawyers tend not to ask too many questions. Consequently, semiotics is, at best, misunderstood by lawyers; more likely it is wholly unknown.

This roundtable seeks to understand how lawyers are the makers and managers of meaning in a much deeper way than most lawyers would understand this phrase. The question motivating my intervention in this discussion is a simple one: why is there such a large disconnect between a sophisticated understanding of law's semiological properties and the practice of law? To re-phrase the question: Why do lawyers understand their practice at such a superficial level? I already have suggested an initial, general answer to this question. Most lawyers would regard something as exotic as semiotic philosophy to have no relevance to the real world of lawyering. And, if semiotics can't help a lawyer to win a case or to succeed in a negotiation, lawyers will see little point in learning about what appears to be solely an academic dalliance.

There are two general responses to this anti-intellectualism. First, one might argue that lawyers will become better lawyers if they understand semiotics, even if there is no semiotic methodology that can be studied, memorized and then applied in legal practice. Second, one might claim that the lawyer's avowed instrumentalism is the very problem to be addressed, and then suggest that semiotic insights can assist us in understanding why lawyers suffer from this malady. This article principally addresses the second point, but also suggests that this critical approach indirectly sheds light on how we might improve legal education in order to educate more effective lawyers.

To provide a focus for my discussion, I wish to recall the famous oration delivered by Giambattista Vico at the University of Naples exactly 300 years ago. The scope of On the Study Methods of Our Time is breathtaking: with the Cartesian "critical method" rapidly gaining ascendence in intellectual circles, Vico argued on behalf of the humanistic tradition. Vico's defense is neither ill-informed nor atavistic; he fully appreciated the power of the Cartesian method, but he also anticipated that its power would prove to be overbearing. He conceded that we must embrace the new rationalism, but that we should do so only without sacrificing ancient wisdom.' Vico's lament is not that we have abandoned a glorious intellectual past, but that we have failed to fulfill the intellectual promise of our future. Vico could see clearly the emerging trends in Western intellectual history

\footnotetext{
${ }^{1}$ As described by Elio Ginaturco, Vico

sets the seal of a philosophical conclusion upon the Quarrel of the Ancients and the Moderns. Vico draws, so to speak, the final balance-sheet of the great controversy; not only that, but transposes it to a ground where the problem posited can receive a solution. He is a reconciler of the two factions; he lifts their debate to a high philosophical plane, he rises to the concept of a modern culture harmonizing the scientific with the humanistic aspects of education.
}

See [1, pp. xxiii-xxiv]. 
that we now recognize have led to lawyers losing their capacity to be managers of meaning and instead becoming technicians who are managed by meaning. ${ }^{2}$

\section{On the Study Methods of Our Time}

Vico begins his oration with a reminder that all human knowledge is partial and fallible, and therefore that we should always be ready to assess our beliefs and correct them. However, he exhorts his audience to recognize that Cartesian radical doubt undermines not only false beliefs that should be discarded but also beliefs grounded in the probable, without which we could not live. ${ }^{3}$ The critical method undermines the cultivation of common sense, which subtends both practical judgment and eloquence, thereby restricting knowledge to an arid and abstract intellectualism [3, p. 13]. This is particularly harmful because the art of making arguments through an inventive use of commonplaces "is by nature prior to the judgment of their validity," and so the art of rhetoric should be granted priority rather than being suppressed. It is important to stress that Vico does not seek to abandon the Cartesian method in order to return to ancient rhetoric. Instead, he counsels a prudent understanding of the role that each can play: "a severely intellectualistic criticism enables us to achieve truth, while ars topica makes us eloquent. ... Each procedure, then has its defects. The specialists in topics fall in with falsehood; the philosophical critics disdain any traffic with probability" [3, pp. $17,19]$.

Vico argues that relentless criticism leaves no room for the rhetorical arts, but it is only in rhetorical engagement that we can deal with questions that admit of no definitive answer. The law purports to seek certainty, but when this goal is understood to mean "truth" in the sense of the Cartesian method it becomes a debilitating straitjacket for legal practice.

Nature and life are full of incertitude; the foremost, indeed, the only aim of our [rhetorical] "arts" is to assure us that we have acted rightly. ... Those who know all the loci, i.e., the lines of argument to be used, are able (by an operation not unlike reading the printed characters on a page) to grasp extemporaneously the elements of persuasion inherent in any question or case. ... In pressing, urgent affairs, which do not admit of delay or postponement, as most frequently occurs in our law courts ... it is the orator's business to give immediate assistance ... Our experts in philosophical criticism, instead, whenever they are confronted with some dubious point, are wont to say: "Give me some time to think it over!" [3, p. 15].

\footnotetext{
${ }^{2}$ Just prior to submitting this essay for publication, Jan Broekman helpfully pointed me to an essay by Thomas Sebeok in which he connects Vico to the modern semiotics movement. Sebeok concludes that "the Vichian project as such has not had much directly traceable effect on modern semiotic inquiry or methodology" [2, p. 137], but he suggests connections between Vico and semioticians such as Peirce, Ibid., pp. 135-136.

${ }^{3}$ Indeed, if a person were to try to live life by utilizing only Cartesian reasoning she would be incapable of action and most likely would be regarded as having a serious mental disturbance.
} 
Rhetoric is necessary just because life is uncertain. The Cartesian philosopher vainly seeks to determine the truth of the matter and therefore is impotent in the face of a pragmatic question of choosing between two proposed courses of action. In contrast, one who is capable of determining the relevant arguments "for and against" the proposed action on the basis of the probabilities of the given circumstances, and is then able to persuade others as to the best approach, exhibits a wisdom that is superior for this task than the more limited scope of definitive truth.

Vico provocatively compares the ability to "grasp extemporaneously" the lines of argument to "reading the printed characters on a page." We speak colloquially about "reading a situation," but Vico is suggesting that we take this metaphor to a deeper level. The abstract characters that form a written language are capable of generating an infinite number of expressions as speakers combine them in new and inventive ways over time. Reading social situations is not an unmediated perceptual facility; rather, it is an art that develops over time as one develops familiarity with the commonplaces that can be deployed in creative ways. An education in eloquence is an education in arraying lines of argument inventively to respond to the situation, and this art rests on ingenuity in "seeing" which arguments best match the situation. The sage understands that this capacity is distinct from philosophical criticism, and is not so foolish as to "apply to the prudent conduct of life the abstract criterion of reasoning that obtains in the domain of science" [3, p. 35].

Rhetoric is not just coequal with philosophy. Rhetoric has temporal priority over philosophy because one must first locate the means of persuasion within a given situation before it is even possible to test the reasoning with philosophical criticism. This is not to suggest that all prudential decisions can or should be subjected to second-guessing by the philosopher. Many of life's issues simply are not amenable to philosophical analysis in the Cartesian tradition; instead, they call for mature judgment that Vico identifies with the ancient rhetorical tradition. The ingenuity of finding similarities among seemingly different factors, the imaginative capacity to create a new understanding of reality, and the prudence to choose appropriately when the matter is not subject to calculation: these are the humanistic capabilities that Vico championed, despite the vigorous Cartesian criticism that their uncertain basis introduces the possibility of error. The sage must be committed to truth, but also ready to act when the frailties of the human condition preclude an analysis that demonstrates the truth of the matter. The sage, "through all the obliquities and uncertainties of human actions and events, keeps his eye steadily focused on eternal truth, manages to follow a roundabout way whenever he cannot travel in a straight line, and makes decisions, in the field of action, which, in the course of time, prove to be as profitable as the nature of things permit" [3].

These considerations lead directly to Vico's recommendations for organizing education. Building on the oration he had delivered in the previous year, ${ }^{4}$ Vico insists that students must first develop their rhetorical skills before being introduced to philosophical criticism. Vico fears that the student might lose forever her capacity for ingenuity, imagination and eloquence if she is exposed to the abstract

\footnotetext{
${ }^{4}$ See [4, pp. 125-140]. The Sixth Oration of 1707 has been titled by the translators, "On the Proper Order of Studies."
} 
intellectualism of the Cartesian method without first cultivating the humanistic arts. In a detailed discussion of law and legal education Vico brings his thesis to bear in very concrete ways. Beginning with the presumption that it is counter-productive to organize a practice that depends on common sense into a system of precepts, Vico recounts the emergence of law as a distinct discipline. The Greeks regarded law as a site of the activity of conjoining philosophy and oratorical skills [3, p. 49]. Similarly, the Romans maintained written laws strictly, but utilized legal fictions that were generated by the orator to avoid injustice [3, pp. 50-52].

In modern times, though, the law has expanded beyond the stark written text and enveloped within itself the moderating force of equity as a matter of interpretation rather than eloquence [3, p. 59]. The law now claims the mantel of justice, which represents both a positive development and a loss: although the law has become directly equitable, we have now lost the connection between law and eloquence, commonly understood as wisdom speaking appropriately to the given situation. Vico regards it as a clear advantage that "the professions of legal expert and orator are, in our age, joined in the same person" [3, p. 62], but as justice was absorbed into law it became too easy for private parties to manipulate the levers of legal authority for their own gain. It was the decay of eloquence in favor of the pursuit of self-interest, Vico emphasizes, that sealed Rome's fate [3, p. 69]. The law has now become a fully self-sufficient discourse that is susceptible to technical manipulation because there is no external discourse to which it must answer through rhetorical argumentation. The problem facing eighteenth-century European society, he believes, is the need to bring legal doctrine back into contact with eloquence and practical wisdom [3, pp. 69-70].

One might wonder if Vico's reference to law and legal education in the oration is wholly happenstance, such that the musings of this eighteenth-century rhetorician have no intrinsic connection to law. In fact, Vico was educated in law, sought a Chair on the law faculty, wrote one of his early works on law, and rooted his thinking in legal reasoning and eloquence. Donald Kelley's reading of Vico leads him to suggest that the modern "social and cultural sciences seem to be the ghosts of dead jurisprudences" 5 as capaciously understood by Vico, and that it was jurisprudence as a "human system of moral, social, and political thought ... rather than the tradition of Greek, scholastic, or Cartesian metaphysics that provided Vico with his principal model and central ideas." ${ }^{6}$ In a similar assessment, Michael Mooney emphasizes that Vico's conception of "rhetoric" was "not a literary but judicial rhetoric-rhetoric as argumentation, a process of reasoning," and that his New Science was premised on the belief that the principles of argumentative discourse provide access to the origin of humanity and undermine the intellectualist fantasy expressed by the Cartesian critical method. ${ }^{7}$ Law is not just an example of

\footnotetext{
${ }^{5}$ See $[5$, p. 611$]$.

${ }^{6}$ See [6, p. 27]. Kelley concludes that the "debts owed by Vico to jurisprudence are incalculable and in some cases almost indemonstrable ... for they involve matters not only of content but of form and method, not only exempla but, much more significantly, also principia of human behavior." Ibid., p. 19.

${ }^{7}$ See [7, p. xiii, 82-83].
} 
one practice among many for Vico. Law is the practice in which our civic life is born and renewed, and it is of central importance to Vico's philosophy. ${ }^{8}$

Vico's oration speaks directly to the question that motivates my paper. A technocratic approach to law and legal education suppresses the imagination and intellectual virtues necessary to practice law in a manner that genuinely unites eloquence-which Vico defines as "wisdom, ornately and copiously delivered in words appropriate to the common opinion of mankind" legal doctrine. Legal hermeneutics has supplanted rhetoric, but it remains ignorant of its rhetorical core and devolves into a deductive-empirical exercise of identifying the "original meaning" intended by the drafters or the "plain meaning" of the legal text before the court. The law is now justice, but a methodological hermeneutics that seeks certainty in the application of the law undercuts this dimension of contemporary legal practice, and as a result lawyers devolve into the mouthpieces of a voiceless wisdom that is equipped only to manipulate legal formulae. It is no overstatement to say that Vico foresaw at the dawn of the modern rationalist era that lawyers would lose their ingenuity and become technocrats who are managed by legal symbols instead of them being equipped to exercise their roles as managers of meaning.

Vico provides much more than a critique of the nascent rationalism of the modern era. He also charts a positive account of the rhetorical means by which signs are woven into constantly-changing narratives. By situating Vico's lament in his oration within his broader philosophical project we can recover this positive dimension of his philosophy and connect his defense of rhetoric to modern semiotic insights. In this way we can locate in Vico's approach not only the he diagnosis of semiotic illiteracy among lawyers, but also can chart the path to its cure.

\section{Vico's Philosophy of Rhetoric}

We may now pose my question with greater specificity and ask whether Vico adds substantial philosophical depth to the assessment of law and legal education by articulating how lawyers can be more effective managers of legal meaning. The ambitious scope of Vico's thought makes clear that he regarded the issues raised in his oration to be linked intimately to fundamental philosophical questions. This is perhaps best revealed by returning to Vico's metaphor of the educated student being able to "see" the best line of argument in a given situation. A rationalist would misinterpret Vico's prescription as suggesting that one first list the possible lines of argument, "view" them, and then deduce the correct answer for the situation. In the legal setting, this misinterpretation is enacted by students who enter the final exam with an outline of the legal doctrine that they have studied and then proceed to recite the rules. The mechanistic application of a list of solidified doctrines is not a genuine "seeing" of the situation in Vico's sense, but rather a "cognizing" or

\footnotetext{
${ }^{8}$ In a recent Symposium that I edited, several contributors focused on the centrality of law to Vico's thinking. See [8-10].

${ }^{9}$ See [3, p. 78$]$.
} 
"calculation" of the situation. This error reflects the Platonic bias that sight provides unmediated access to a stable reality, rather than resulting from an active engagement with one's surrounding. Vico is describing the cultivation of a capacity to deal with a symbolic system in a sophisticated and inventive manner rather than being consigned to manipulate the symbols according to a pre-existing logic.

Vico famously celebrates the significance of the sensus communis, but by this he does not mean the "common sense" of the populace in the sense of shared but untested and unreflective beliefs. Rather, Vico's "common sense" refers to the manner in which the individual senses are united in the making of a pre-reflective world on which later intellectual efforts rest. Ernesto Grassi develops this dimension of Vico's thought in his description of the two fundamental forms of human expression: the rational and the rhetorical. The former is timeless and universal, while the latter is apt and contextual. ${ }^{10}$ The distinct realm of the rhetoricalcharacterized as an ingenious grasp of commonalities through metaphoric "sight"is fundamental. Rationality gains no traction without the pre-existing world that arises out of human imagination, which is intended to be taken in its literal sense as the formation of "images" by which one "sees" the world.

Vico's "ingenious method"-studying topics and learning how to persuade others in a situation of uncertainty-is a recommendation to use one's common sense to imagine new solutions to problems, to "see" a new path of persuasion by drawing connections that are not already recognized. A well-chosen metaphor does just this, carrying meaning from one situation to a new situation, seemingly instantaneously as if we suddenly see something that previously had been hidden from view. ${ }^{11}$

${ }^{10}$ See [11, pp. 96-97]. Grassi elaborates:

This 'ingenious' metaphorical and fantastic activity is not realized in the framework of rational logic but in "common sense" [sensus communis] through which we continually transform reality in the human context by means of 'fantastic' concepts. In such a language we never meet with abstract human beings but rather with those who, like ourselves, find themselves through work, in temporal and spatial relationships. The concepts through which we come to understand and 'grasp' each situation come from our ingenuous, metaphorical, fantastic capacities that convey meanings in the concrete situations with which we are confronted.

Fantastic universals have a primacy over abstract rational ones because concrete reality is revealed through them. For instance in Cicero's previously mentioned example the expression 'happy sowing' is not rational and so not 'scientific' in the traditional sense, but rather expresses the meaning which sowing has for human beings, a relationship (happy) which the supposedly 'true' rational expression never would reveal. The same holds for the other example from Cicero, 'when the shot escapes the hand.' It aims at showing and revealing that which is really experienced and hence the concrete time in which human beings find things to receive a new meaning through work.

The conformity of reality to human needs comes about through human work, and this occurs through the conveyance of meaning in which fundamental metaphors reveal concrete reality, not in the frame of universal, abstract, rational language.

Ibid., p. 100.

11 Grassi notes that the original meaning of "metaphor" was to physically carry an item from one place to another, but that gradually it came to be used "metaphorically" as a transfer of meaning that Aristotle recognized as being foundational to education because it generated knowledge not through a chain of deductions that might fail but rather through immediate insight (Ibid., pp. 94-95). 
The ingenious faculty assumes the important function of supplying arguments which the rational process itself is not capable of "finding" ... But it is exclusively on the basis of revealing common elements that a transfer can be made, and that is why Vico defines the ingenious faculty as a requisite for metaphorical thought. ... Based on the ingenious faculty, which establishes relationships or common factors, imagination, according to Vico, confers meanings on sense perceptions. Through its transfers, imagination is the original faculty of "letting see" (phainestai), so that Vico calls it "the eye of the ingenium" [12, p. 562].

Exercising the imagination through topical argumentation is necessary because there is no substitute for the accumulation of experience. One cannot become prudent by deducing answers to practical problems; one becomes prudent through the exercise of judgment based on "insight," which is really a "new sight," or a "broadened sight." To express this metaphorically, it might be possible to improve one's eyesight by using one's eye in a certain manner, as happens by the use of a patch to force the other eye to focus properly, but we can be sure that reading about the biological structure of our optical sensations will not improve this capacity. It is a matter of exercising one's capacity through experience, rather than one's cognitive achievements. Vico urged us to recognize that we can improve our ingenious capacity through proper education, the education in the liberal arts. ${ }^{12}$

Vico's oration relates to law directly, but not superficially. Seen within the context of his life's work, the oration is premised on a view of knowledge and human understanding that confronts the Cartesian critical approach at the deepest philosophical levels rather than just suggesting that different educational methodologies that might be employed. Vico's ingenious method-training students in the art of argumentation-develops the capacity of their imagination to see the world in new ways. This is not just training students to learn rhetorical tricks that can be mastered and then packed into the lawyer's toolkit for later use. Instead, Vico's

\footnotetext{
${ }^{12}$ Michael Mooney makes this point vividly:

Ingenuity, Vico says repeatedly, is the "faculty of bringing together things that are disparate and widely separated." It lays no claim to thoroughness or method, but is a capacity, as Petrarch had said of it, which is quick and decisive, penetrating and acute, ready and adaptive. One does not need to call on ingenuity; one either has it or does not, sees connections or misses them utterly. Vico was a child of acute ingenuity, he claimed, and so, too, are children generally, if only we will recognize it and train them accordingly. For ingenuity depends on the images of fantasy, a faculty most vivid and robust in youth, and on the power of memory, fantasy's twin, and they in turn take their start in sensations, the images of sense. But the point is more subtle than it seems, for sense and memory are not to be thought of as mere passive capacities, receiving and retaining impressions that imagination and ingenuity subsequently work through; sense, memory, imagination, and ingenuity are four virtually indistinguishable aspects of the single, prediscursive action of the mind.

Ingenious perception is truly an invention, an assembling and arranging of images that produces a genuinely novel vision. ... [In] oratory and law, it is a vision of how things should be, a course of action that will set things right or avoid their deterioration, a vision that joins past to future through current expectations, thus achieving plausibility, but one that does so through images that are familiar and foreign alike, thus opening to us new ways. Such images are those of metaphor, language that is sententious and acute.
}

See [7, pp. 151, 153]. 
educational program was designed to facilitate the student's ability to enter and move about a semiotic realm by using rhetorical competencies. Lawyers are particularly in need of such an education, because they rarely ground their arguments in certain truths and almost always must negotiate the symbolic order of law through rhetorical engagement with others.

\section{Educating Lawyers with Semiotic Sensibility}

In this concluding section I offer a preliminary outline of how Vico's oration provides a productive lens through which to view the semiological properties of law and the implications for legal education. Vico wrote at a momentous time in the intellectual history of the West, and he wrote with the full conviction that his lessons were not effete academic theories but instead concerned the possibility for the continued development of Western culture. Scholars of his New Science (see [13]) might debate whether Vico was a historical determinist, but there can be no mistake that he believed in the efficacy of human agency at the time he delivered On the Study Methods of Our Time. ${ }^{13}$ Vico's sense of urgency and pragmatism, united with his comprehensive approaches to history and philosophy, illuminate our condition quite vividly.

Vico's intellectual orientation holds significant advantages for contemporary legal theorists. He does not resign himself to the concession that human culture is trapped within the "prison-house" of language, confined within an autopoetic system that overwhelms individual agency. Vico regards the creative insight of the rhetor as an important factor in the ongoing elevation of man out of nature. At the same time, Vico does not endorse a crude humanist account of subjective agency that assumes that individuals can rise above their cultural context and survey it as a

\footnotetext{
13 I concur with Mark Lilla that the New Science can be read as continuous with Vico's earlier oration.

If civilized Athens and mighty Rome were both undone by the "barbarism of reflection," is there any hope of nations today escaping their fate? ... In his pre-scientific works Vico's practical political teaching is clear enough: preserve the traditions and religious customs by which divine providence directs you to the verum, forswearing the enticements of modern enlightenment, and you shall be like Rome. But those earlier works treat only of Rome's exemplary rise, ignoring her fall.

By studying the collapse of Rome at the end of her historical corso he now hopes to unmask the forces that robbed her of those traditional strengths. Those lessons could then be applied to European societies through the ricorso, which puts Europe in Rome's place and reveals which of its "Roman" traditions must be defended against the new barbarization.

On this reading, the corso-ricorso doctrine is not a scientific doctrine. It is a prophecy, a dramatic warning to modern Europe that she stands at the edge of an abyss. No reader has come away from the final packed pages of the New Science without sensing their prophetic rhetorical power. Just as in On Method, where he once called modern Europeans to revive ancient education, Vico again seems to be calling Europe away from its modernity.

His practical teaching is therefore relatively clear: societies wishing to maintain their perfection must learn to strengthen all that is Roman within themselves, and direct all that is Greek within them to serve these Roman virtues. Philosophy can retain a role in maintaining this equilibrium, though only as the handmaiden of science and religion. Philosophy must now choose to assist "common sense" rather than weaken it through skepticism.
}

See [14, pp. 217, 225-227]. 
geographer might. Vico recognizes that we exist in and through semiotic narratives such that there is no human subject capable of willing meaning into being. Vico warns against the hubris of seeking knowledge of things divine in an effort to become wholly self-directing, but at the same time he insists that we are capable of achieving knowledge of human affairs and shaping them. In short, Vico propounds a rhetorical philosophy that is closely tied to civic and political engagement but that also displays a sophisticated appreciation of the semiotic character of this engagement. By returning to Vico we find a starting point from which we may embark on a path that avoids the Charybdis of "just playing" and the Scylla of endless self-consuming deconstruction.

Vico's use of the metaphor of sight to describe rhetorical knowledge is an illuminating trope for thinking about educating lawyers with semiotic sensibility. The goal of legal education should not be to instill knowledge of legal rules, or even to teach students how to "think like a lawyer." Rather, legal education should be a formative experience through which students come to inhabit a new world in which they move about as one moves about in a physical place. The ancient topics, loci communes, operated literally as "common-places" in which a community resided and within which members exhibited a "common sense." It is important not to misunderstand Vico's metaphor by presuming that one's senses are passive receptors of abiding stimuli; to the contrary, seeing is an active engagement with one's surroundings, an evolving ability to move within commonplaces and through exercising commonsense. There is no abiding truth to be seen, but rather arguments to be taken up by uniting imagination with eloquence.

Vico argues that we can develop lawyering "sight" through the ingenious method of rhetorical instruction. Arguing both sides of a case in response to a specific problem by working within the commonplaces, students develop the capacity for the sophisticated semiotic activities of lawyering. We should conceive legal education as educating students about how to make arguments that can never meet the strictures of logical thinking, bringing to bear Aristotle's famous distinction between rhetoric and dialectic. For example, students must learn to deploy metaphors in the course of legal argumentation in order to learn how to find the available lines of argument for securing the adherence of their audience. A wellchosen metaphor leads the hearer to a conclusion immediately, as if gazing at the conclusion immediately in front of her eyes; in fact, of course, the conclusion is predicated on a complex body of tacit semiological knowledge and education that cannot be methodically manipulated to generate the conclusion in an effective manner. Through the practice of using metaphors in the course of a legal education, students begin to see the world differently with an aim of being able to lead others to see the world differently as well.

We might say that legal education is like learning to have a good sense of humor and a quick wit: if one tries to learn the "rules" of telling a joke the exercise will be a complete failure. One learns only by telling jokes, testing what works, and habituating oneself to find the right quip at the right time without being able to think through the situation completely. The well-chosen metaphor comes to the lawyer just as a well-chosen riposte comes to the stand-up comedian: the process is 
incredibly complex and the result of focused education, but it cannot be learned as one might learn calculus.

Law students must learn to manage legal meaning, but this education should not be confused with the business model of "management" through the issuance of directives. Lawyers participate in a semiotic economy without being able to control or direct it. Perhaps this point can be expressed only metaphorically. The semiotic inheritance that lawyers take up is like the block of marble with which Michelangelo began his famous sculptures. Michelangelo was a consummate artist, but he knew that the marble would not bend to his will and yield any figure he chose. His famous half-completed works in the great hall of the Accademia leading to the magnificent David-appropriately known as "the prisoners"-famously exhibit Michelangelo's thesis that sculpture was the art of removing extraneous marble from the slab to reveal the figure within. He began by "revealing" the torsos, and the incomplete figures appear to be fighting to free themselves from the remaining marble. Michelangelo was incredibly creative, but his creativity was brilliant because he responded to the medium and worked within it rather than seeking to subjugate it. The David is a case in point, as it was "freed" from a gigantic slab of marble deemed unusable by other artists working at the Duomo, and is now a timeless tribute to one who managed the meaning of that particular piece of marble.

Lawyers make meaning and attempt to manage it on behalf of their clients. Managing legal meaning does not mean dominating legal symbols and producing meaning ex nihilo, nor does it mean subservience to a closed economy of selfperpetuating symbols. Rather, lawyers manage meaning by embracing their creative role within a common place, inhabiting the legal realm in such a way that they can see the appropriate lines of argumentation struggling, like Michelangelo's "prisoners," to be free of the encrustations of what once were creative acts of lawyering. Vico's prescient warning and call to action speaks to us still.

Acknowledgments I am very grateful to Jan Broekman for inviting me to his seminar, from which I learned a great deal, and for being such a generous cicerone. I also thank Bill Pencak for his active and illuminating participation in the seminar. Both Professor Broekman and Professor Pencak made very helpful suggestions for revising this paper, but I remain responsible for the inadequacies that remain. This paper draws heavily from a longer work. See [15].

\section{References}

1. Ginaturco, Elio, trans. 1990. Translator's introduction. In Giambattista Vico: On the study methods of our time, xxi-xlv. Ithaca, NY: Cornell University Press.

2. Sebeok, Thomas A. 2001. Some reflections on Vico in semiotics. In Global semiotics, 135-145. Bloomington, IN: Indiana University Press.

3. Vico, Giambattista. 1990. On the study methods of our time (trans: Elio Ginaturco). Ithaca, NY: Cornell University Press. (Trans: Orig. Pub. 1965; Book Orig. Pub. 1709).

4. Vico, Giambattista. 1993. On humanistic education: Six inaugural orations (trans: Girogia A. Pinton and Arthur W. Shippee). Ithaca, NY: Cornell University Press.

5. Kelley, Donald R. 1976. In Vico veritas: The true philosophy and the new science. Social Research 43: 601-611. 
6. Kelley, Donald R. 1976. Vico's road from philology to jurisprudence and back. In Giambattista Vico's science of humanity, ed. Giorgio Tagliacozzo and Donald Phillip Verene. Baltimore, MD: The Johns Hopkins University Press.

7. Mooney, Michael. 1994. Vico in the tradition of rhetoric. Davis, CA: Hermagoras Press.

8. Verene, Donald Phillip. 2008. Vichian moral philosophy: Prudence as jurisprudence. Chicago-Kent Law Review 83: 1107-1130.

9. Bayer, Thora Illin. 2008. Vico's principle of sensus communis and forensic eloquence. Chicago-Kent Law Review 83: 1131-1155.

10. Sherwin, Richard K. 2008. Sublime jurisprudence: On the ethical education of the legal imagination in our time. Chicago-Kent Law Review 83: 1157-1196.

11. Grassi, Ernesto. 1980. Rhetoric as philosophy. University Park, PA: The Pennsylvania University Press.

12. Grassi, Ernesto. 1976. The priority of common sense and imagination: Vico's philosophical relevance today. Social Research 43: 553-580.

13. Vico, Giambattista. The new science (trans: Thomas G. Bergin and Max H. Fisch). Ithaca, NY: Cornell University Press.

14. Lilla, Mark. 1993. G.B. Vico: The making of an anti-modern. Cambridge, MA: Harvard University Press.

15. Mootz III, Francis. 2008. Vico's "ingenious method" and legal education. Chicago-Kent Law Review 83: 1261-1302. 